\title{
The leafhopper subgenus Empoasca (Matsumurasca) from China (Hemiptera: Cicadellidae: Typhlocybinae: Empoascini), with descriptions of three new species
}

\author{
DAO-ZHENG QIN ${ }^{1}$, YA-LIN ZHANG ${ }^{2}$ \\ Key Laboratory of Plant Protection Resources and Pest Management of Ministry of Education, Entomological Museum, Northwest A \\ \& F University, Yangling, Shaanxi Province, 712100, China. E-mail: ' qindaozh0426@yahoo.com.cn; ${ }^{2}$ yalinzh@yahoo.com.cn; \\ ${ }^{2}$ corresponding author
}

\begin{abstract}
The empoascine leafhopper subgenus Empoasca (Matsumurasca) Anufriev is redescribed. Four species, including three new species from China are reported: E. (M.) clypeata sp. nov., E. (M.) biloba sp. nov. and $E$. (M.) quadrifida sp. nov. New distributional records for E. (M.) onukii Matsuda are provided. A key to distinguish all species of the subgenus worldwide is also provided.
\end{abstract}

Key words: Homoptera, Empoasca (Matsumurasca), distribution, taxonomy, China

\section{Introduction}

The empoascine subgenus Matsumurasca of the genus Empoasca Walsh was established by Anufriev (1973), with E. diversa Vilbaste (1968) as the type species, and including some allied species in the Empoasca aino Matsumura (1931) group mentioned by Dworakowska (1971). The subgenus is among the 12 subgenera of Empoasca and is characterized mainly by the stalked or triangular third apical cell of the forewing, subgenital plate being prominently broad at the base and aedeagus often with paired processes (Anufriev, 1973). Empoasca (Matsumurasca) currently contains 9 described species widely distributed in the Palaearctic and Oriental regions: E. (M.) aino Matsumura, E. (M.) onukii Matsuda, E. (M.) dolichi Paoli, E. (M.) conifera Dworakowska, E. (M.) latissima Dworakowska, E. (M.) parvifacia Dworakowska, E. (M.) thapae Dworakowska, E. (M.) schima Thapa, and the type species. Empoasca $(M$.$) onukii reported earlier from Hangzhou,$ Zhejiang Province, China was studied by Dworakowska $(1971,1982)$.

In the present paper, the subgenus is redescribed. Four species known to occur to China, including three species new to science are described and illustrated along with new distributional records for E. (M.) onukii.

\section{Material and methods}

Except for the nomenclature of the wing, for which we follow Dworakowska (1993), the methods and terminology used in this work follow Zhang (1990). The specimens used in this study are deposited in the Entomological Museum, Northwest A \& F University, Yangling, Shaanxi, China (NWAFU) and Institute of Zoology, Chinese Academy of Science, Beijing, China (IZCAS). 


\section{Results}

\section{Subgenus Empoasca (Matsumurasca) Anufriev}

Empoasca (Matsumurasca) Anufriev, 1973: 540.

Type species: Empoasca diversa Vilbaste, 1968, by original designation.

Green to yellowish-green species. Body relatively robust. Anterior margin of crown roundly protuberant and continuous with outer margin of eyes, posterior margin broadly concave, anterior and posterior margins of crown subparallel, middle length of vertex less than width between eyes. Coronal suture distinct. Face broad, anteclypeal and frontoclypeal areas apparently swollen. Pronotum large, longer than crown. Scutoscutellar sulcus distinct. Forewing with 2nd apical cell slightly broadening towards apex; $\mathrm{c}$ and $\mathrm{r}$ cells nearly equal in width, narrower than $m$ and cua cells; veins RP, MP' arise from $r$ cell and MP" $+\mathrm{CuA}$ ' from $m$ cell, 3rd apical cell stalked or triangular, 4th apical cell shortest.

Abdominal apodemes well developed, parallel sided. Male pygofer elongated, with rigid macrosetae on each side of pygofer lobe; ventral appendage present. Subgenital plate far exceeding pygofer, base prominently broadened and triangularly protruded basolaterad, lateral macrosetae forming an irregular double row merging into a single row distally, reaching apex of plate, short marginal microsetae occupying almost half length of anterior margin. Paramere serrate apically, setae and sensory pits basad of apical serrations. Connective lamellate. Aedeagus with preatrium long, dorsal apodeme absent or undeveloped. Anal tube process developed or not.

Discussion: Anufriev (1973) in his original description of the subgenus states that "some Oriental species of the genus, in particular some mentioned in Linnavuori's paper (1960), may perhaps be included in the subgenus Matsumurasca too". Linnavuori (1960) reported 20 species of Empoasca from Micronesia. However, some of these species, including macarangae Metcalf and fuscovitta Metcalf have been transferred to the genus Austroasca (Dworakowska, 1971); boninensis (Matsumura) has been transferred to Austroasca (Jacobiasca) (Dworakowska, 1972). Empoasca sesuvii Linnavuori has been transferred to Sundapteryx (Dworakowska, 1970), but Sundapteryx was later regarded as a synonym of Amrasca (Dworakowska \& Viraktamath, 1975), this species should be excluded from the subgenus Matsumurasca because it has the subgenital plate narrow basally. For the same reason, Empoasca esakii Linnavuori, crenulata Linnavuori, dentistylus Linnavuori, xanthopus Linnavuori, pitiensis Metcalf and yona Metcalf should also be excluded from subgenus Matsumurasca. Empoasca pipturi Metcalf, bipunctulata Metcalf, barringtoniae Metcalf, colorata Linnavuori, morindae Metcalf also should be excluded from this subgenus as they lack the stalked or triangular 3rd apical cell of the forewing. Empoasca nocturna Linnavuori is not member of the subgenus because all apical veins arise from the m cell. Empoasca acuticeps Linnavuori should not be included in the genus because it lacks a ventral pygofer appendage. Empoasca fumatipennis Linnavuori probably also should not be placed in the genus because it has the pygofer lobe strongly narrowing terminally and abdominal apodemes strongly diverging.

The remaning two species of Empoasca included by Linnavuori (1960) namely, ngatpangensis Linnavuori and puncticeps Linnavuori are also not members of the subgenus because the two species have the crown subangularly produced at the anterior margin, the pronotum small, in puncticeps the vertex nearly as long as pronotum and parameres not serrate at apex; and in ngatpangensis the ventral pygofer appendage free only in apical part and abdominal apodemes rather diverging.

As noted above, the authors describe below three new species in the subgenus.

Distribution: China (Zhejiang, Hainan, Hunan, Sichuan, Fujian, Yunnan, Sichuan, Henan, Hubei, Gansu), USSR, Korea, Japan, Vietnam, India. 


\section{Key to species of the subgenus Empoasca (Matsumurasca) Anufriev (males)}

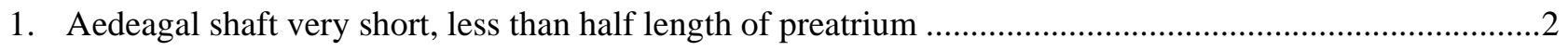

Aedeagal shaft long, with nearly same length, or even longer than preatrium..........................................

2. Ventral pygofer appendage apparently bent caudodorsad in basal third and adorned with tufted hairs in apical third, apex smooth on ventral side

E. (M.) clypeata n. sp.

Ventral pygofer appendage slightly curved dorsad in middle portion and adorned with sparse minute hairs subterminally, apex delicately serrated on ventral side

E. (M.) parvifacia

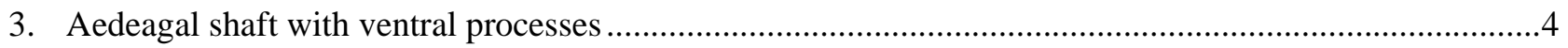

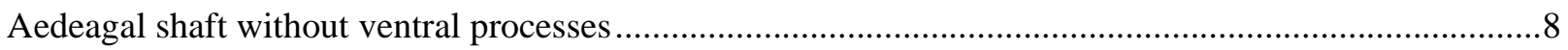

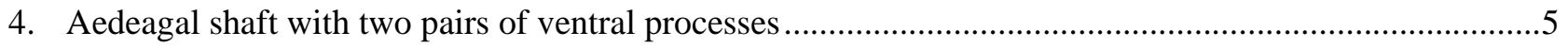

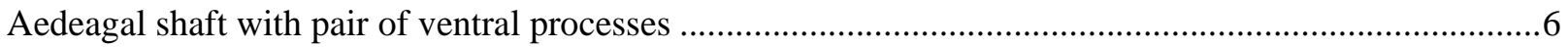

5. Aedeagal shaft with two pairs of processes ventrobasally ............................................... E. (M.) thapae

Aedeagal shaft with pair of basal processes and subapical processes respectively

E. (M.) quadrifida n. sp.

6. Aedeagal shaft curved in lateral view, gonopore subterminally on ventral side E. (M.) dolichi Aedeagal shaft nearly straight in lateral view, gonopore terminal

7. Ventral pygofer appendage sinuate, exceeding caudal margin of the lobe.

E. (M.) diversa Ventral pygofer appendage bent dorsad at its base, not exceeding caudal margin of the lobe. E. (M.) aino

8. Aedeagal shaft dorsally armed with a pair of flange-like processes. E. (M.) biloba $\mathbf{n} . \mathbf{s p .}$ Aedeagal shaft dorsally without flange-like processes.

9. Ventral pygofer appendage serrated terminally or subterminally, or coarsely sculptured subterminally..10 Ventral pygofer appendage smooth, sinuate near apex, not serrated or coarsely sculptured. E. (M.) onukii

10. Ventral pygofer appendage serrated terminally or subterminally. .11 Ventral pygofer appendage coarsely sculptured subterminally, not serrated ........................ E. (M.) schima

11. Ventral pygofer appendage serrated terminally, exceeding caudal margin of pygofer lobe E. (M.) conifera Ventral pygofer appendage serrated subterminally at ventral side, not exceeding caudal margin of pygofer lobe E. (M.) latissima

\section{Empoasca (Matsumurasca) clypeata, n. sp.}

(Figs. 1-13)

Type materials. Holotype, male (NWAFU), Dahaoping, Tengchong, Yunnan Province, 26 Nov. 1999, 19502000 m, coll. Irena Dworakowska. Paratypes, 1 ox, 25 Nov. 1999, 2000 m; $2 \sigma^{x}, 26$ Nov. 1999, 1950-2000 m,

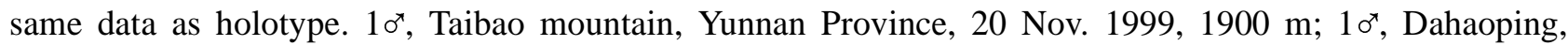
Tengchong, Yunnan Province, 24 Nov. 1999, 2000 m; 10, Jindian, Kunming, Yunnan Province, 2 Jan. 2000, coll. Daozheng Qin (NWAFU).

Length. Male $4.0-4.3 \mathrm{~mm}$.

Colour. Vertex yellow, with a grayish-green patch centrally on each side of coronal suture; ocelli surrounded by ivory patch; coronal suture beige. Eyes grayish-black. Frontoclypeal area and genae yellow; anteclypeus yellowish-green, apical half light blue green. Pronotum with lighter patches at anterior margin and arcuate area behind eyes; scutellum with quadrate creamy patch antero-mesally. Forewing and hind wing hyaline. Abdomen yellow. Legs yellow except 1st-2nd tibiae and tarsi and 3rd tarsi sordid blue green.

Abdominal apodemes parallel-sided, rather obliquely truncate apically, surpassing half of 5th segment. Male pygofer elongated, terminal part rather quadrangular in outline, 10-13 rigid setae on each side of pygofer lobe; ventral pygofer appendage bent dorsocaudad in basal third and exceeding caudal margin of pygofer lobe, adorned with numerous hair-like outgrowths in caudal third before tapering in apical 1/4 to a 
pointed apex. Subgenital plate with basal group of 2-3 long, thick setae, 13-17 short marginal microsetae, 1723 long lateral macrosetae and fine microsetae arranged in 2-3 irregular rows. Paramere broad in basal part, narrowing to short curved apical part, with 5 closely placed teeth preceeded by $2-3$ setae. Aedeagal shaft very short, less than half length of preatrium, obliquely truncate apically, in caudal view aedeagus slightly expanded in apical third and narrowing basad, gonopore ventrad near apex. Connective broad, anterior margin thickened, caudal margin incised medially. Anal tube process very short, swollen at base and abruptly narrowing to pointed apex.

Female. Unknown.

Etymology. The species name is treated as a adjective and refers to the peculiar clypellus.

Discussion. Empoasca (Matsumurasca) clypeata n. sp. rsembles Empoasca (Matsumurasca) parvifacia Dworakowska, 1994, but differs in being longer (4.0-4.3 mm compared to 3.7-4.0 $\mathrm{mm}$ in E. (M.) parvifacia); the ventral pygofer appendage is apprently bent caudodorsad in basal third and adorned with tufted hairs in apical third and the anal tube process very short, swollen basally and abruptly narrowing to pointed apex.

\section{Empoasca (Matsumurasca) biloba, n. sp.}

(Figs. 14-26)

Type materials. Holotype, male (NWAFU), Shenlongjia, Hubei Province, 29 Jul. 2001, coll. Min Huang \&

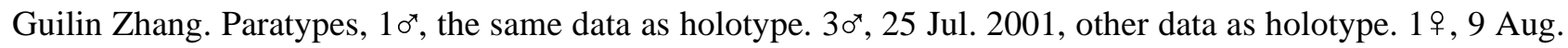
2001, Hengshi, Tongshan County, Hubei Province, coll. Min Huang. 10 $0^{\star}$, Tianping mountain, Sangzhi, Hunan Province, 14 Aug. 2001, coll. Qiang Sun, light trap. 2 ๙ $^{\star}$, Sangzhi, Hunan Province, 3 Sept. 1981, coll. Xinwang Tong. $10^{x}$, Emei mountain, Sichuan Province, 30 Oct. 1999, 800 m, coll. Daozheng Qin (NWAFU).

Length. Male 4.1-4.5 mm, Female $4.3 \mathrm{~mm}$.

Colour. Vertex yellowish-green, area between ocelli somewhat sordid, with grayish-green patch on each side of vertex centrally and longitudinal creamy streak along coronal suture not reaching anterior margin, bordering eye with creamy patch basally at each side; ocelli surrounded by creamy patch mesocaudad; coronal suture beige. Eyes blackish-brown. Frontoclypeal area yellow, with small creamy patches in anteocular areas and at base centrally; anteclypeus yellowish, apical half light blue green; genae yellowish-green. Along anterior margin and arcuate area in anterior part of pronotum with 3 irregular creamy patches and a quadrate creamy patch in centre of scutellum anteriorly. Forewing and hind wing hyaline. Abdomen yellow. Legs sordid green, 3rd tibia and 3rd tarsus in basal half yellow.

Abdominal apodemes parallel-sided, reaching end of $4^{\text {th }}$ segment. Male pygofer elongated, almost quadrangular, dorsal margin slightly sinuate, with 7-9 stout setae on each side of pygofer lobe; ventral pygofer appendage exceeding pygofer lobe, apical 1/6 curved and tapering to a pointed apex. Anterior margin of subgenital plate broad in apical 2/5, with 2-3 microsetae in basal group, 16-22 short marginal microsetae, 20-23 long lateral macrosetae and fine microsetae arranged in 2-3 irregular rows. Paramere solid, apex almost truncated, subapical region with 7 teeth preceeded by about 5-6 setae. Aedeagal shaft in lateral view nearly twice as long as preatrium, broad basally and narrowing distally, apical $1 / 3$ continuously curved with apex pointed and directed ventrad, shaft with pair of flange-like processes, gonopore dorsad near apex. Connective with anterior margin thickened and caudal margin incised medially. Anal tube process long, lamellate in side view, broad at base, apical part sinuate and abruptly tapering to pointed apex.

Female. Body colour similar to male.

Etymology. The name of this species is treated as a adjective, refering to the two flange-like processes on the aedeagal shaft.

Discussion. Empoasca (Matsumurasca) biloba, n. sp. can be distinguished from other species of the subgenus by the subgenital plate being very broad basally and the aedeagal shaft dorsally armed with a pair of flange-like processes. 

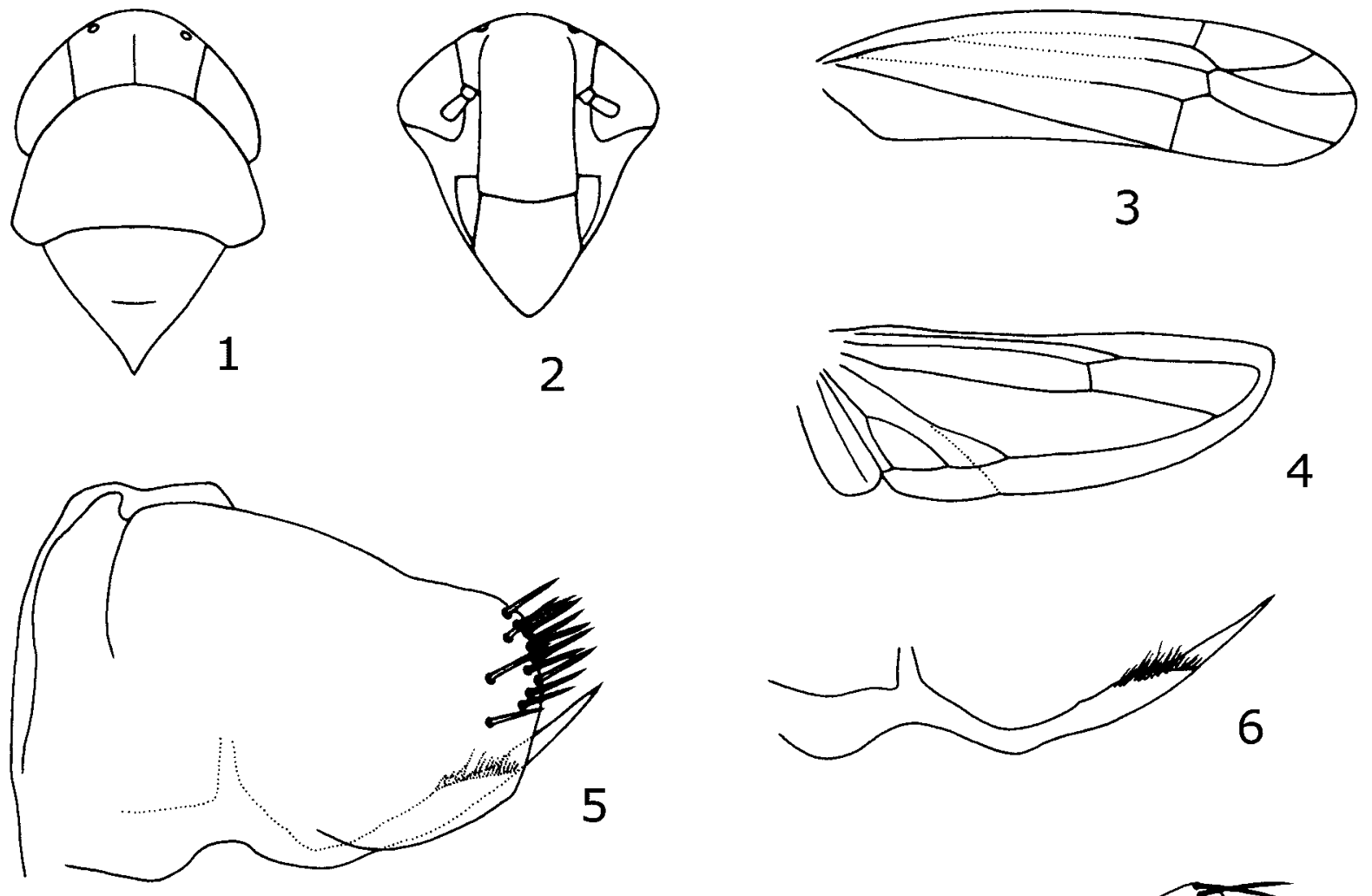

4

5
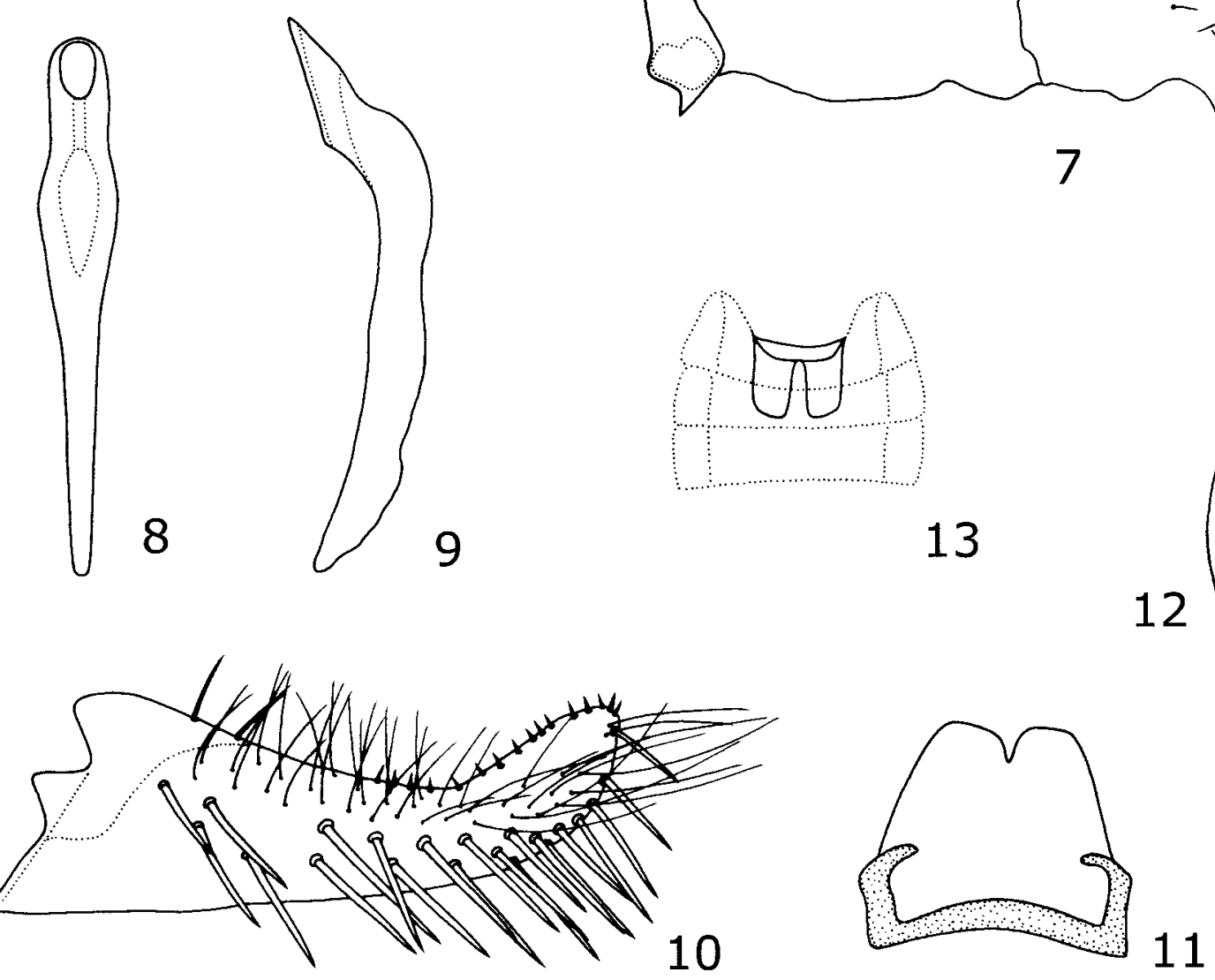

6

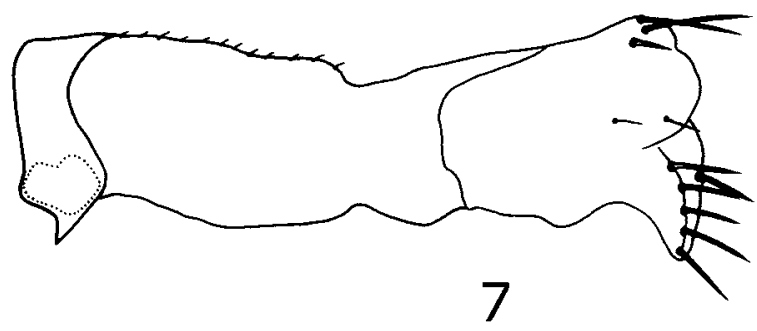

FIGURES 1-13. Empoasca (Matsumurasca) clypeata n. sp., 1, head and thorax, dorsal view; 2, face; 3, fore wing; 4, hind wing; 5, pygofer, lateral view; 6, ventral pygofer appendage; 7, anal tube and anal styli; 8, aedeagus, caudal view; 9 , same, lateral view; 10, subgenital plate; 11, connective; 12, paramere; 13, abdominal apodeme. 

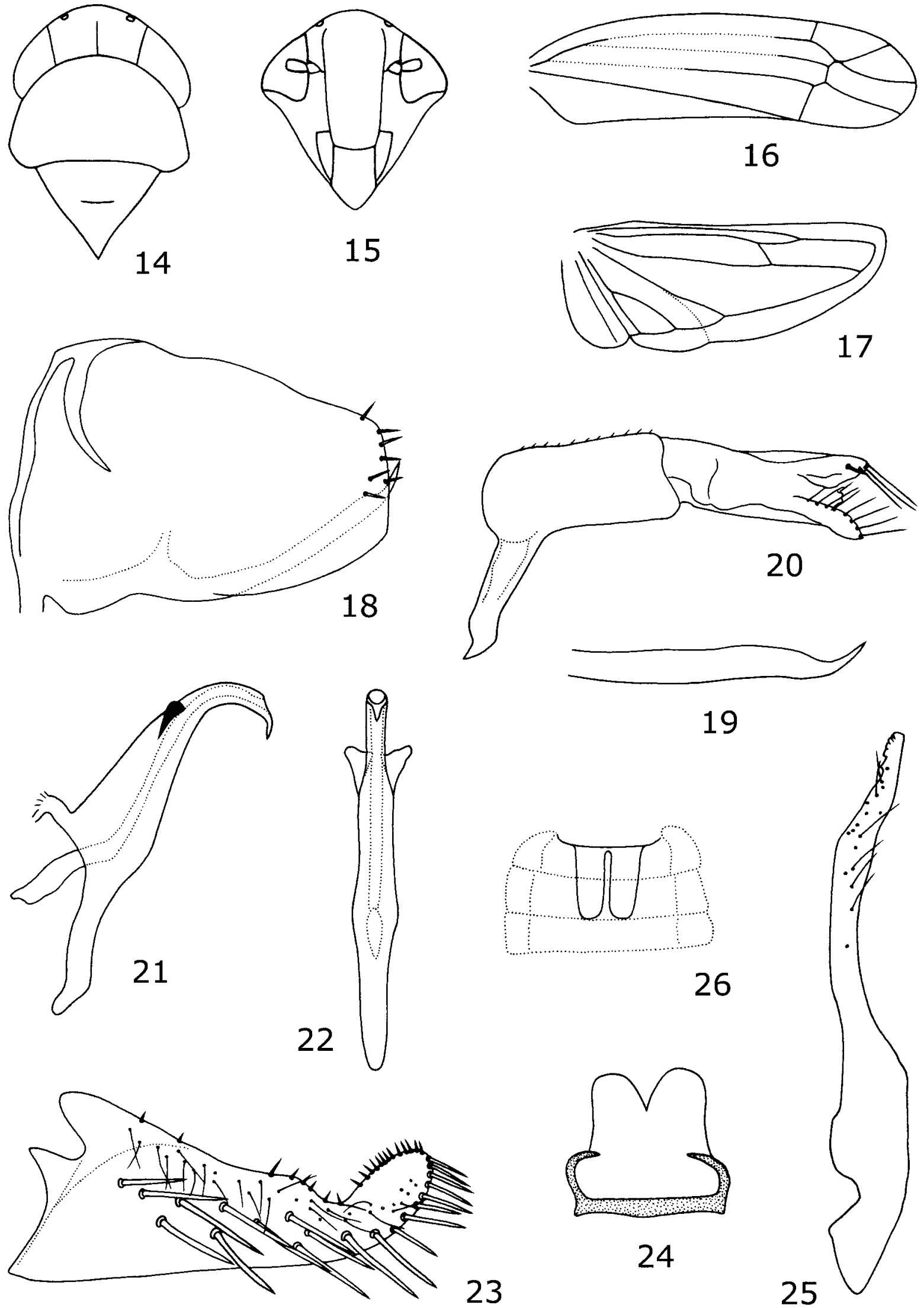

FIGURES 14-26. Empoasca (Matsumurasca) biloba n. sp., 14, head and thorax, dorsal view; 15, face; 16, fore wing; 17 , hind wing; 18 , pygofer, lateral view; 19 , ventral pygofer appendage; 20 , anal tube and anal styli; 21 , aedeagus, lateral view; 22 , same, caudal view; 23 , subgenital plate; 24 , connective; 25 , paramere; 26 , abdominal apodeme. 


\section{Empoasca (Matsumurasca) quadrifida, n. sp.}

(Figs. 27-40)

Type material. Holotype, male (NWAFU), Mianning County, Sichuan Province, 8 Nov. 1999, 1650 m, coll.

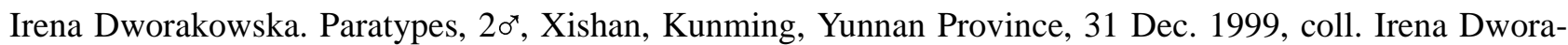

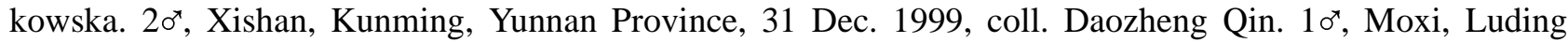
County, Sichuan Province, 4 Nov. 1999, 1600 m, coll. Daozheng Qin (NWAFU).

Length. Male 4.0-4.1 mm.

Colour. Vertex yellow, with grayish-green patch centrally on each side of coronal suture; ocelli surrounded by creamy patch; coronal suture beige. Eyes brownish. Frontoclypeal area greenish-yellow, basal part yellow; anteclypeus light yellow to greenish-yellow; genae yellow. Pronotum with lighter patches at anterior margin and arcuate area behind eyes; scutellum with quadrate creamy patch antero-mesally, basal angles sordid yellowish. Forewing and hindwing hyaline. Abdomen yellow. Legs yellow except 1st-3rd tibia apically and tarsus sordid greenish.

Abdominal apodemes parallel-sided, rounded apically, reaching end of 5th segment. Male pygofer quadrangular, with 5-8 stout setae on outer surface; ventral pygofer appendage curved caudodorsad, not exceeding caudal margin, curved dorsad and tapering to pointed apex. Subgenital plate with 3-5 microsetae in basal group, 15-21 short marginal microsetae, 18-21 long lateral macrosetae and fine microsetae arranged in 2-3 irregular rows. Paramere with subapical dentate region with 4 teeth preceeded by $4-6$ setae. Aedeagal shaft longer than preatrium, with basal pair of long spinose processes and subapical pair of short processes, dorsal apodeme well developed, gonopore terminal. Connective with anterior margin thickened, caudal margin incised medially. Anal tube process solid, lamellate, median part broadened then tapering to acute apex.

Female. Unknown.

Etymology. The new species name alludes to the two pairs of processes on the aedeagal shaft.

Discussion: Empoasca (Matsumurasca) quadrifida, n. sp. is similar to Empoasca (Matsumurasca) thapae, but differs from the latter in having an apically pointed ventral pygofer appendage compared to the deeply serrated ventroapical margin found in $E$. (M.) thapae; the paramere with the subapical region bearing 4 teeth without denticles on its surface; the abdominal apodemes almost reaching the end of the $5^{\text {th }}$ segment; the aedeagal shaft longer than the preatrium, with basal and subapical pairs of processes.

\section{Empoasca (Matsumurasca) onukii Matsuda, 1952}

Empoacsa onukii Matsuda, 1952; Dworakowska, 1971: 505. Empoasca (Matsumurasca) onukii, Dworakowska, 1982: 52.

Specimens examined: $10^{\star}, 30$ Aug. 1985; $20^{\star} 1$ 우, 31 Jul. 1985; $10^{\star}, 3$ Aug. 1985; $10^{\star} 1$ 우, 4 Aug. 1985; $10^{\star}, 8$ Aug. 1985; $10^{x} 2$ 우, 10 Aug. 1985; $10^{\star}$, 13 Aug. 1985; $10^{\star} 1$ 우, 16 Aug. 1985; $10^{x} 1$ 우, 18 Aug. 1985, Chenzhou, Hunan Province. 10, 29 Jul. 1985, Mang mountain, Chenzhou, Hunan Province. $10^{x}$, 11 Aug. 1985, Heng mountain, Hunan Province, specimens above were collected by Yalin Zhang and Yonghui Chai. $10^{x}$, Diaoluoshan, Hainan Province, 4 Jul. 1983, coll. Yalin Zhang, light trap. 10, Guadun, Wuyi, Fujian Province, 20 Aug.

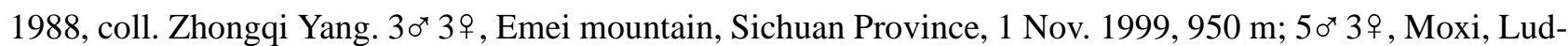

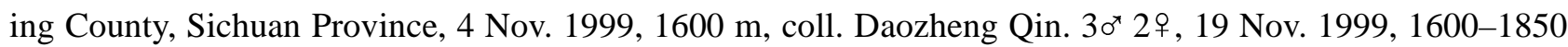
m; 60 8우, 20 Nov. 1999, 1750-1900 m, Taibao mountain, Baoshan County, Yunnan Province; $10^{\star}$, Lingcang

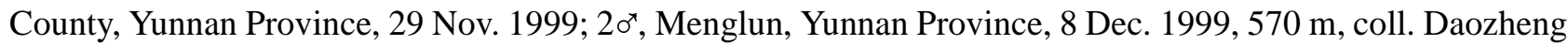

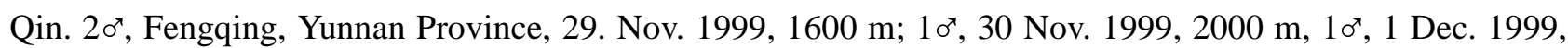
Lingcang, Yunan Province, 1700 m, coll. Irena Dworakowska. 10, Jigong mountain, 11 Jul, 1997, coll. Jian Hu. 10 $\sigma^{x}$ Bikou, Wen County, Gansu Province, 25 Jun. 1998, 900-1450 m, coll. Xingke Yang (NWAFU, IZCAS $\left.10^{x}\right)$. 

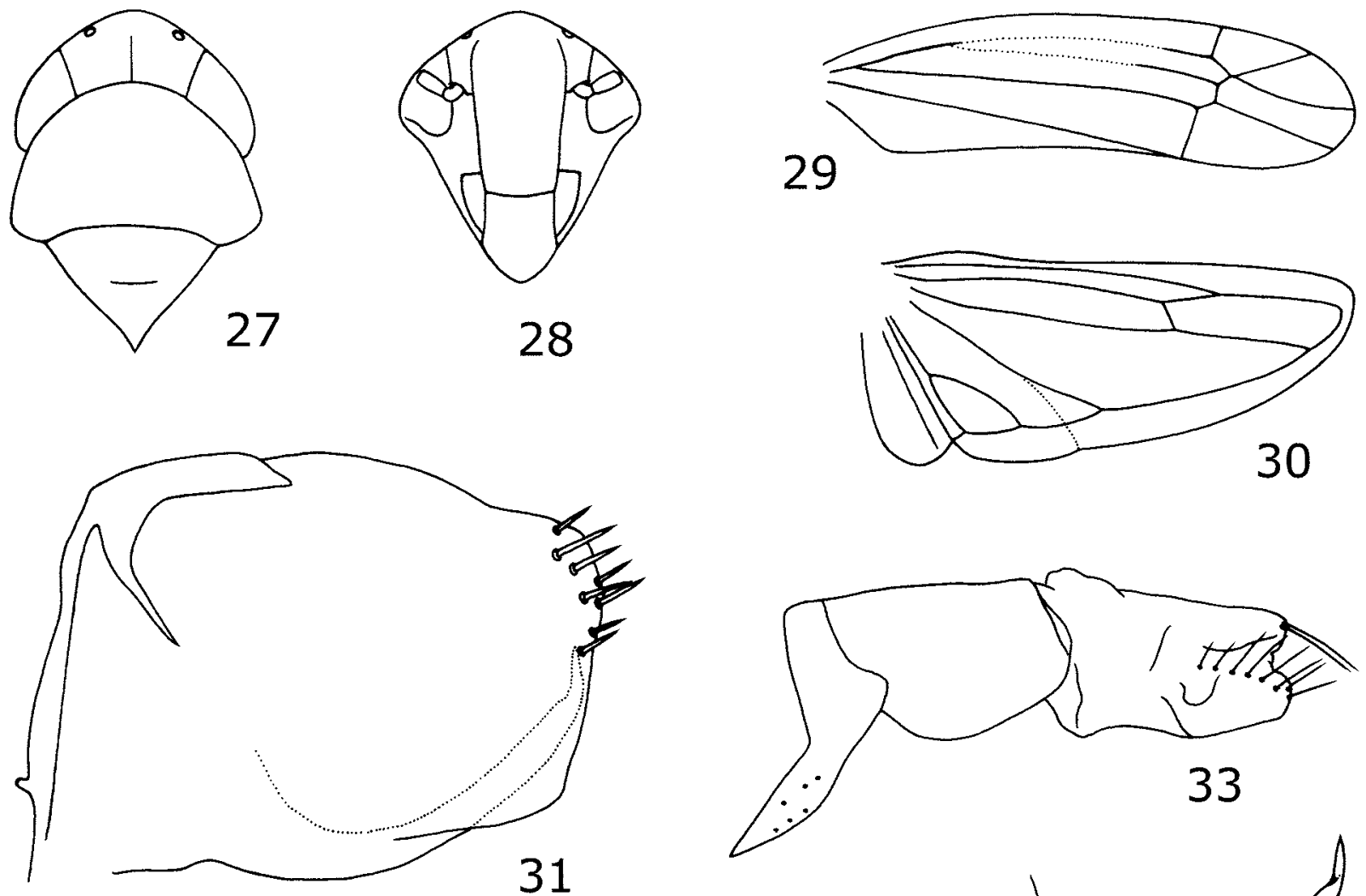

30
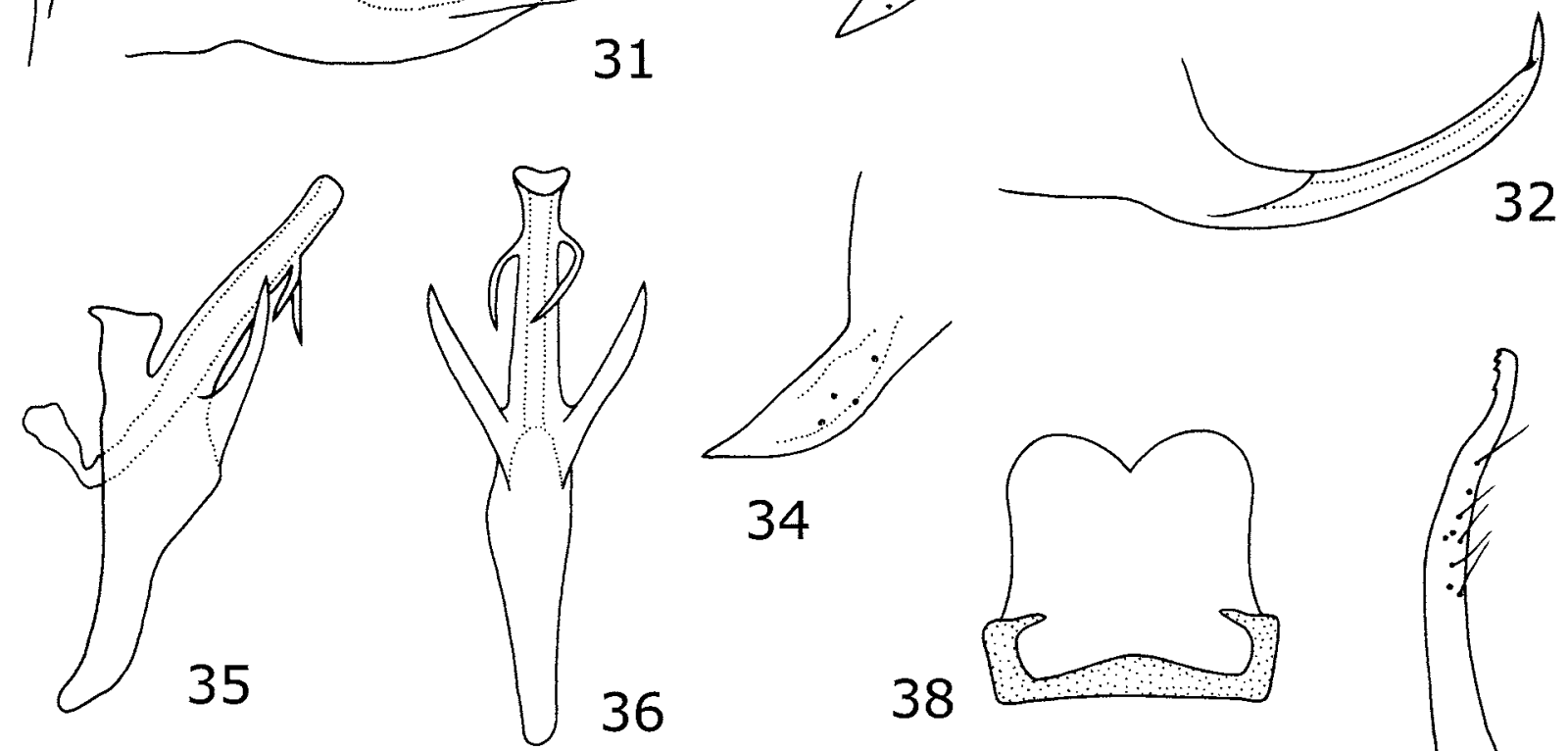

32
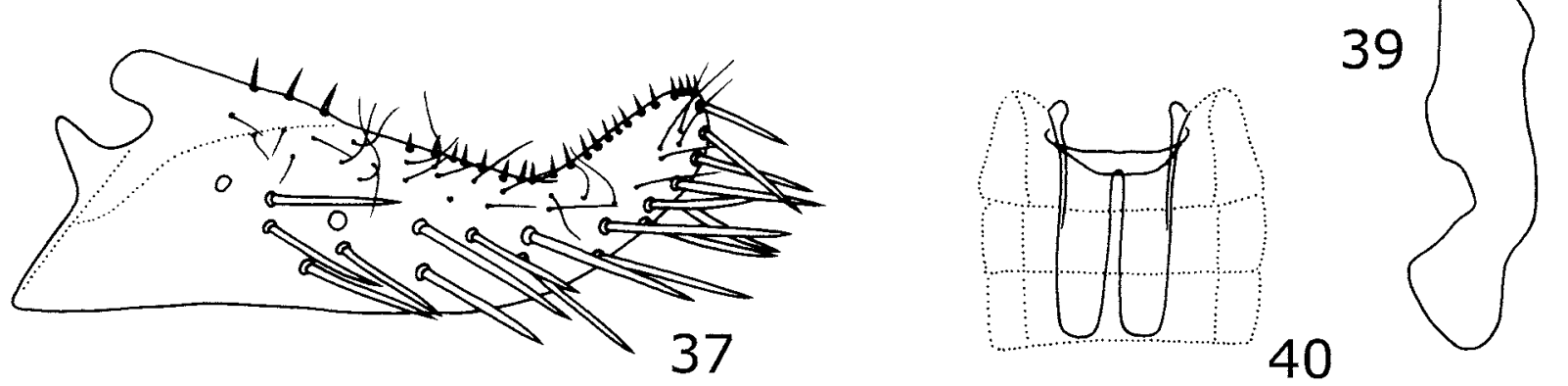

FIGURES 27-40. Empoasca (Matsumurasca) quadrifida n. sp., 27, head and thorax, dorsal view; 28, face; 29, fore wing; 30, hind wing; 31, pygofer, lateral view; 32, ventral pygofer appendage; 33, anal tube and anal styli; 34, anal tube process; 35, aedeagus, lateral view; 36, same, caudal view; 37, subgenital plate; 38, connective; 39, paramere; 40, abdominal apodeme. 
Distribution: China (Hainan, Zhejiang, Hunan, Sichuan, Fujian, Yunnan, Henan, Gansu Provinces), Japan, Vietnam. Except the previous record in Hangzhou, Zhejiang Province, China by Dworakowska (1971, 1982), other distributional records are new.

\section{Acknowledgements}

We are very grateful to Dr. Sterling Southern, Department of Entomology, North Carolina University, USA; Mr. Mick Webb, The Natural History Museum, London and Dr. C. A. Viraktamath, the University of Agricultural Sciences, Bangalore, India for reviewing the manuscript and suggesting improvements. We also thank Dr. Chris Dietrich for his kind editorial help with this paper. This study was supported by the Pilot Project of Standardized Curation, Data Integration and Resource Sharing of Zoological Collections (2005DKA21402) and "Northwest A \& F University Grant for Young Academic Talent (01140301)" and Special Science Program of NWAFU (08080253)".

\section{References}

Anufriev, G.A. (1973) The genus Empoasca Walsh, 1864 (Homoptera, Cicadellidae, Typhlocybinae) in the Soviet Maritime Territory. Annales Zoologici, 30, 537-558.

Dworakowska, I. (1970) On some genera of Typhlocybini and Empoascini (Auchenorrhyhcha: Cicadellidae: Typhlocybinae). Bulletin de l'Academie Polonaise des Science. Serie des Sciences Biologiques, 18, 707-716.

Dworakowska, I. (1971) Dayus takagii sp. n. and Some other Empoascini (Auchenorrhyncha: Cicadellidae: Typhlocybinae). Bulletin de l'Academie Polonaise des Science. Serie des Sciences Biologiques, 19, 501-509.

Dworakowska, I. (1972) On some Oriental and Ethiopian genera of Empoascini (Auchenorrhyncha: Cicadellidae: Typhlocybinae). Bulletin de l'Academie Polonaise des Science. Serie des Sciences Biologiques, 20, 25-34.

Dworakowska, I. \& Viraktamath, C.A. (1975) On some Typhlocybinae from India (Auchenorrhyncha, Cicadellidae). Bulletin de l'Academie Polonaise des Science. Serie des Sciences Biologiques, 23, 521-530.

Dworakowska, I. (1981) On some Typhlocybinae from India, Sri Lanka and Nepal (Homoptera, Auchenorrhyncha, Cicadellidae). Entomologische Abhandlungen und Berichte aus dem staatlichen Museum fur Tierkunde in Dresden, 44, 153-202.

Dworakowska, I. (1982) Empoascini of Japan, Korea and north-east part of China (Homoptera, Auchenorrhyncha, Cicadellidae, Typhlocybinae). Reichenbachia, 20, 33-57.

Dworakowska, I. (1993) Remarks on Alebra Fieb. and Eastern Hemisphere Alebrini (Auchenorrhyncha: Cicadellidae: Typhlocybinae). Entomotaxonomia, 15, 91-121.

Dworakowska, I. (1994) Typhlocybinae (Auchenorrhyncha: Cicadellidae) of Sikkim, a preliminary survey, Folia Entomologica Hungarica, 55, 93-215.

Linnavaori, R. (1960) Insects of Micronesia. Homoptera: Cicadellidae. Bishop Museum, Honolulu, Hawaii, 6, 231-344.

Matsumura, S. (1931) A revision of the Palaearctic and Oriental Typhlocybid-genera with description of new species and new genera. Insecta Matsumurana, 6, 55-92.

Vilbaste, J. (1968) Systematic treatise of Cicadas found on the edge of costal regions. Uber die Zikadenfauna des Primorje Gebietes. lzdatel'stvo "Valgus", Tallin. 195pp.

Zhang, Y.L. (1990) A taxonomic study of Chinese Ciadellidae (Homoptera). Tianze Eldonejo. Yangling, Shaanxi, China. $218 \mathrm{pp}$. 